\title{
PROCESSO DE ENSINO DE GEOGRAFIA NA EJA, BOA VISTA/ RR, E SUA CONTRIBUIÇÃO PARA O DESENVOLVIMENTO SUSTENTÁVEL ${ }^{1}$
}

\section{ARTIGO ORIGINAL}

SOUZA, Jorge Luíz Pedrosa De ${ }^{2}$

CORONEL, Derlis Ortiz ${ }^{3}$

SOUZA, Jorge Luíz Pedrosa De. CORONEL, Derlis Ortiz. Processo de ensino de geografia na EJA, Boa Vista/ RR, e sua contribuição para o desenvolvimento sustentável· Revista Científica Multidisciplinar Núcleo do Conhecimento. Ano 04, Ed. 10, Vol. 01, pp. 100-105. Outubro de 2019. ISSN: 2448-0959, Link de acesso: https://www.nucleodoconhecimento.com.br/educacao/ensino-de-geografia

\section{RESUMO}

Apresenta os resultados de uma pesquisa da análise do ensino de geografia na modalidade EJA, nas escolas de Boa Vista, e sua contribuição para o desenvolvimento sustentável. Observou-se a investigação aos professores e alunos de ensino médio e fundamental, para 150 alunos e 14 professores, selecionados de forma aleatória em 30\% e 100\% respectivamente do universo das escolas, utilizando como instrumento o questionário contendo questões objetivas e subjetivas. Os dados foram sistematizados e analisados à luz de autores como: Gadotti (2000); Nóvoa (1997b); Paulo Freire (1998b). Verificou-se a importância do ensino da geografia no poder conscientizador, para um crescimento intelectual e discursivo às leis ambientais. Havendo necessidade de mudanças nas técnicas de ensino (quadro

${ }^{1}$ Parte da dissertação de Mestrado do autor, apresentada à Universidad Politécnica Y Artística Del Paraguay - UPAP.

${ }^{2}$ Mestre Em Ciências Da Educação; Especialista Em Recursos Naturais; Bacharel Em Agronomia; Pedagogo; Licenciado Em Geografia.

${ }^{3}$ Doutorado em Doctorado en Ciencias de la Educación. 
negro, livros, etc), na materialização da práxis pedagógica ao minimizar dificuldades, cabendo ao docente priorizar alternativas autossustentáveis na conservação e preservação dos ecossistemas.

Palavras-chave: Geografia, desenvolvimento sustentável, modalidade EJA, professores, alunos.

\section{INTRODUÇÃO}

Com o processo de democratização se vislumbrou um novo divisor de águas, onde se observou uma mudança no posicionamento do homem como ator social, colaborando e descobrindo novos princípios de uma educação denominada de sócio construtivista, que culmina com a inserção dos Parâmetros Curriculares Nacionais (PCN's), buscando assim atingir metas que referendassem a nova política neoliberal de um Estado democrático que oferecesse educação para todos, corroborando a um sistema de educação massiva, porém, com baixa qualidade atrelada a grandes projetos sociais eleitoreiros.

Entretanto, no contexto da formação de professores observamos um resgate do papel importante na caracterização de uma nova profissionalização docente, fazendo com que surja uma nova cultura profissional e organizacional dentro das escolas. Verificase o esquecimento sistemático do desenvolvimento pessoal, confundindo-se segundo Nóvoa (1997b, p. 24), "formar" e "formar-se", não se compreendendo que a lógica da atividade educativa nem sempre coincide com as dinâmicas da própria formação.

E ainda, nessa formação de professores, mais do que um espaço de aquisição de técnicas e de conhecimentos, é o momento chave da socialização e configuração profissional. Considerando que cada indivíduo faz parte de um contexto social diferente, sua formação acontece na medida em que estiver predisposto a auto educar-se, auto-aperfeiçoar-se. A formação não pode ser por acúmulo de cursos de conhecimento ou técnicas. É necessário acima de tudo um trabalho de reflexão crítica sobre as práticas e de re-construção permanente de uma identidade pessoal. (Nóvoa, 1997b). 
É importante destacar que, quando se fala em formação de professores, estão sendo assumidas ao mesmo tempo posições epistemológicas, ideológicas, culturais, relativa ao ensino, ao professor e aos alunos (SACRISTÁN, 1995).

Partindo para o pressuposto de orientação do papel da escola, comenta Vesentini (1999), a respeito das possibilidades de a escola cumprir atualmente sua dupla função de instituição indispensável à reprodução social e de instrumento de libertação. Segundo ele, atualmente há uma necessidade de elevar a escolaridade da população brasileira em geral:

Essa escolaridade tem que ser fundamentada num ensino não mais "técnico", como na época do fordismo, e sim "construtivista", no sentido de levar as pessoas a pensar por conta própria, aprendendo a enfrentar novos desafios, criando novas respostas em vez de somente repetir velhas fórmulas.(VESENTINI, 1999, p.20).

Por outro lado, vivemos também na era da informação em tempo real, da realidade virtual, da internet, da globalização da economia, da quebra de fronteiras entre nações, do ensino a distância, dos escritórios virtuais, da robótica e dos sistemas de produção automatizados, do entretenimento. Como afirma Gadotti (2000), vivemos o ciberespaço da formação continuada.

Dessa forma, tornou-se evidente que algumas categorias se apresentam mais frequentemente hoje na literatura pedagógica e que atendem às perspectivas atuais da educação do futuro, se expressando na planetaridade, na sustentabilidade, na virtualidade, na globalização e na transdisciplinaridade. (GADOTTI, 2000).

Sabemos, porém, que os problemas atuais, inclusive os ecológicos, são provocados pela nossa maneira de viver, e nossa maneira de viver é inculcada pela escola, pelos valores transmitidos pelos currículos, livros didáticos etc. Por conseguinte, reorientar a educação a partir do princípio da sustentabilidade implica em disseminar novas concepções pedagógicas, tais como a escola cidadã e a ecopedagogia .

Envolto a toda essa contextualização, onde se veem a questão ética e moral relegadas ao descaso da essência maior do saber literário, dissipada em todas as áreas do ensino, é que trabalharemos analisando o processo de ensino da disciplina de 
geografia e a sua contribuição para o desenvolvimento sustentável em uma realidade local de escolas do município de Boa Vista nas áreas central, semi-periférica e periférica envolvendo docentes e discentes da modalidade da educação de Jovens e adultos - EJA.

Para fundamentar esta pesquisa nas concepções e no Desenvolvimento Sustentável foram referenciadas literaturas nacionais e internacionais, tais como: Gadotti (2000); Nóvoa (1997b); Paulo Freire (1998b); Sacristan (1995); Cunha (1994; 2000); Malaguzzi (1999); Katz (1999); Freinet apud Santos (1996); Vesentini (1999); Libâneo (1998) e outros que tratam da temática abordada.

Recorreu-se ainda à Legislação e Normas vigentes no Brasil como a Constituição Federal de 1988, Diretrizes Curriculares Nacionais para a Formação de Professores de geografia, Lei de Diretrizes e Bases da Educação Nacional, № 9.394/96, e Parâmetros Curriculares Nacionais.

Neste trabalho, apresenta-se um conjunto de aspectos inter-relacionados que compõe a área temática, ou seja, objeto de estudo da pesquisa: que é analisar as ideias dos professores e alunos a respeito da disciplina de geografia e a sua contribuição para o desenvolvimento sustentável, a qual se propõe desvendar.

Dessa forma, busca-se mostrar a importância do ensino da geografia para professores e alunos e particularmente sua contribuição para o desenvolvimento sustentável nas escolas estaduais de Ensino Médio e Fundamental do município de Boa Vista, Roraima. Identificar as técnicas de ensino de geografia dos professores para saber se o desenvolvimento sustentável está presente no currículo das escolas públicas estaduais de Ensino Médio do município de Boa Vista-Roraima. E por fim, verificar de que maneira o processo de ensino da geografia se materializa na práxis pedagógica do professor envolvido com o desenvolvimento sustentável nas escolas de Ensino Médio e Fundamental no município de Boa Vista-Roraima. 


\section{MARCO METODOLÓGICO}

O trabalho desenvolveu-se a partir da aplicação do questionário elaborado com 29 questões, sendo 11 abertas e 18 fechadas para os docentes, assim como, para os discentes foram aplicadas 25 perguntas, 6 subjetivas e 19 objetivas. Ao todo foram investigados 150 alunos e 14 professores, selecionados de forma aleatória na composição de $30 \%$ e $100 \%$ respectivamente do universo das escolas discriminado neste estudo, conforme demonstrado no Quadro 01.

Quadro 01: Quantitativo de escolas, número de questionários aplicados e devolvidos e número de gestores entrevistados.

\begin{tabular}{|c|c|c|c|c|}
\hline $\begin{array}{c}\text { Escolas de } \\
\text { ensino Médio } \\
\text { e }\end{array}$ & $\begin{array}{c}\text { Questionários } \\
\text { aplicados aos } \\
\text { professores }\end{array}$ & $\begin{array}{c}\text { Questionários } \\
\text { respondidos } \\
\text { pelos } \\
\text { professores }\end{array}$ & $\begin{array}{c}\text { Questionários } \\
\text { aplicados aos } \\
\text { alunos }\end{array}$ & $\begin{array}{c}\text { Questionários } \\
\text { respondidos } \\
\text { pelos alunos }\end{array}$ \\
\hline A1 & 5 & 4 & 60 & 59 \\
A2 & 5 & 5 & 45 & 45 \\
A3 & 4 & 4 & 45 & 45 \\
\hline TOTAL 3 & $\mathbf{1 4}$ & $\mathbf{1 3}$ & $\mathbf{1 5 0}$ & $\mathbf{1 4 9}$ \\
\hline
\end{tabular}

Fonte: Autor.

Enfim, a metodologia se delineou conforme um tipo investigativo, a qual se expressou num contexto descritivo exploratório, com enfoque norteado numa realidade reflexiva subjetiva (qualitativa), como também, num cenário de visão empírica e objetiva (quantitativa).

A partir de então, consubstanciou-se a pesquisa nas unidades de análise inseridas nas Escolas A, B e C para 14 docentes e 150 discentes, com uso dos questionários e de pesquisa literária durante um espaço amostral de 2 anos, a partir do ano 2009.

Com isso, construímos o quadro abaixo que demonstra, de forma sucinta, todas as informações desenvolvidas durante o trabalho de pesquisa realizado nas escolas. 
Quadro 02: Quadro de esboço do organograma de metodologia da pesquisa

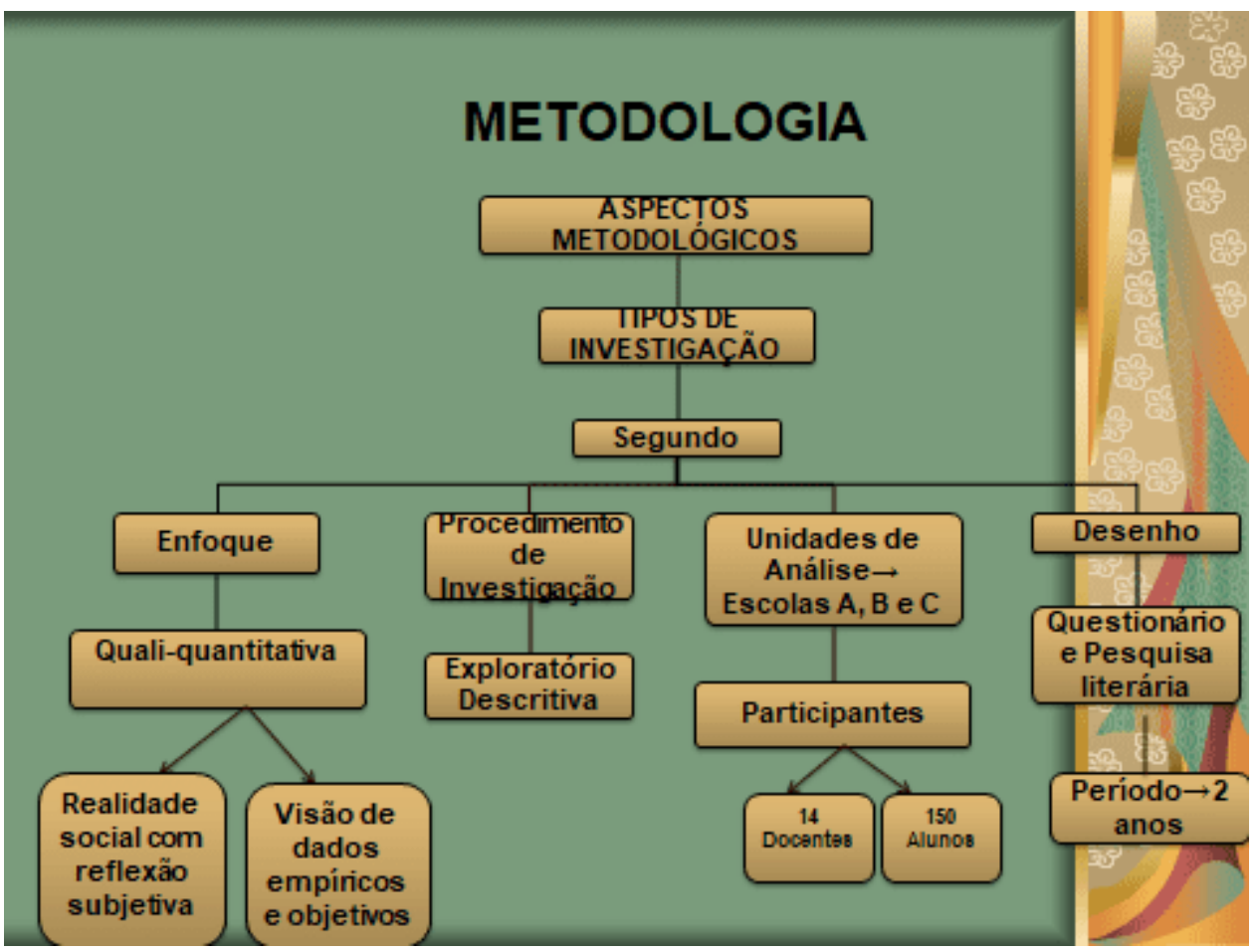

Fonte: Autor.

\section{ANÁLISE E DISCUSSÃO DOS DADOS}

A partir da aplicação dos questionários versando sobre: 1.a .profissionalização do docente, 2 . a cultura da informação tecnológica, 3 . os procedimentos e modalidade de ensino e a absorção de conteúdos na perspectiva da geografia, 4. o sentido de aprendizagem na visão Freiriana e 5. a temática do desenvolvimento sustentável propagada numa educação ambiental de maneira ética e conscientizadora; os dados foram sistematizados e analisados à luz de autores como: Gadotti (2000); Nóvoa (1997b); Paulo Freire (1998b); Cunha (1994; 2000); Malaguzzi (1999); Katz (1999); Freinet apud Santos (1996); Vesentini (1999); Libâneo (1998) e outros que tratam da temática abordada. As conclusões apontaram importante contribuição para os profissionais atuantes na área de geografia, especialmente na modalidade EJA. 


\section{CONSIDERAÇÕES FINAIS}

Assim sendo, se verificou que a importância do ensino da geografia para os professores e alunos se reproduz no poder conscientizador, colaborando para um crescimento intelectual e discursivo no tocante as leis ambientais.

Havendo ainda uma necessidade de mudanças nas técnicas de ensino (quadro negro, livros e mapas), buscando uma resposta pedagógica que contemplem novas metodologias voltadas ao desenvolvimento sustentável, tais como: seminários, estudos dirigidos, projetos e pesquisas de campo.

E por fim, se reconhece a materialização da práxis pedagógica ao minimizar dificuldades (pouco uso de recursos tecnológicos, pouco interesse dos alunos, ausência de aulas de campo), cabendo ao profissional da geografia priorizar um planejamento didático com alternativas autossustentáveis que culmine com a conservação e preservação dos ecossistemas. Neste sentido se pôde determinar a importância do ensino da geografia para os docentes e alunos.

\section{REFERENCIAS}

CAVALCANTI, L. S. Geografia e práticas de ensino. Goiânia : Alternativa, 2002.

CMMAD (Comissão Mundial sobre o Meio Ambiente e Desenvolvimento). Nosso Futuro Comum. Rio de Janeiro: Fundação Getúlio Vargas, 1988.

CUNHA, E.R. - Um estudo sobre o trabalho pedagógico de professores de EJA.. Itajaí: v.9, n.2, p. 51 - 65, mai.- ago. 2009. Disponível em: http://www.google.com.br/ web06.univali.br/seer/index.php/rc/article/view/997/1102; Acesso em:17/02/2015.

FREIRE, Paulo. Conscientização: teoria e prática da libertação. Uma introdução ao pensamento de Paulo Freire. São Paulo: Moraes, 1980.

GADOTTI, Moacir. Pedagogia da Terra. São Paulo: Cortez, 2000; 
GAMBOA, Silvio Sánchez. Pesquisa em educação: métodos e epistemologias. Chapecó: Argos, 2007. 193p.

NÓVOA, A. (Coord.). Os professores e a sua formação. Lisboa: Nova Enciclopédia, 1997

PAIVA, Jane. Trabalho: A Mão na Massa Desafios à LDB: Educação de Jovens e Adultos para um Novo Século? In. ALVES, Nilda e VILLARDI, Raquel (Orgs.) Múltiplas Leituras da nova L.D.B. Rio de Janeiro: Qualitymark/Dunya Ed. 1997.

SACRISTÁN, Gimeno. Consciência e acção sobre a prática como libertação dos professores. In: NÓVOA, A. (Coord.). Os professores e a sua formação. Lisboa: Porto Editora, 1995.

VESENTINI, J. W. O novo papel da escola e do ensino de geografia na época da terceira revolução industrial. Terra Livre, São Paulo, v. 11-12, ago. 92/ ago 93.

Educação e ensino de geografia, instrumentos de dominação e/ou libertação. In: CASTROGIOVANNI. A .C. et al. (Orgs.). Geografia em sala de aula, práticas e reflexões. Porto Alegre: Associação dos Geógrafos Brasileiros, Seção Porto Alegre, 1999.

Enviado: Agosto, 2019.

Aprovado: Outubro, 2019. 